\title{
Exploration and Research on Talent Training Mode of Industry-Education Integration: Based on Intelligent Manufacturing Productive Training Base in the University
}

\author{
Yajuan Chen, Yunxia Qi* \\ Institute of Artificial Intelligence, Chongqing Real Estate College, Chongqing, China \\ *59702318@qq.com
}

\begin{abstract}
The production training base of intelligent manufacturing is built by the university as the carrier of deepening the industry-education integration. It combines the education supply and industrial demand of Intelligent manufacturing talents in China, constructs the personnel training and practice method under the industryeducation integration mode suitable for the corresponding professional development of our university, provides high-quality technical and technical talents for the advanced manufacturing industry, and serves the regional economy development.
\end{abstract}

Keywords: industry-education integration, production line training base, intelligent manufacturing, talent

training

\section{Introduction}

Since the beginning of the new century, Chinese education has been developing vigorously, which has provided a large number of high-quality talents for the socialist modernization and made great contributions to the development of the modern industrial system. But at the same time, influenced by many factors such as system and mechanism, the supply side of talent training and the demand side of industry can't fully adapt to the structure, quality and level. Deepening the industry-education integration, and promoting the organic connection of education chain, talent chain, industrial chain and innovation chain are the urgent requirements for promoting the structural reform of the supply side of human resources. It is of great significance to improve the quality of education, to expand employment and entrepreneurship, to promote economic transformation and upgrading, and to cultivate new energy for economic development in the new situation.

The campus intelligent manufacturing industrial park is taken as the implementation of productive training base, in order to carry out the exploration and practical research of the technical skills training mode under the industryeducation integration.

\section{Research status of industry-education integration}

Combined with the characteristics of regional higher education and industrial development, it can promote the coordinated development of industry-education integration. It can provide high-quality human resources guarantee for economic and social development. It can determine the construction goal of modern vocational education system. Industry-education integration has important enlightenment and demonstration role in many aspects.

Domestic research on the industry-education integration mainly includes three aspects. The first aspect is the research on the industry-education integration mode, such as the research on the type of integration mode, the research on the market adaptability, the development strategy of collaborative innovation. The second aspect is the research on the innovation of the integration mechanism in higher vocational education, including the construction of integration mechanism, the integration cooperation mechanism last aspect is the research on the operation mechanism of the integration.

\section{Problems in the integration of production and education}

Higher vocational education is an important part of our modern vocational education system. It also affects the development of our social economy. How to build a talent training mode of industry-education integration, and to form a high-quality technical and skilled talent training mechanism with its own characteristics is the characteristic development path that almost every higher vocational college is exploring [1]. However, through the investigation and research of various colleges and universities, especially the private vocational colleges, it is found that in addition to the individual colleges and universities, the industryeducation integration has really been achieved, others have not been implemented. In the process of industry-education 
integration, there are mainly the following problems.

First, the mechanism of industry education integration is not perfect. In the process of the industry-education integration, there is a lack of standardized systems, processes, standards and systems. In the process of co construction, there is a lack of guidance, supervision and coordination. The operation mechanism of school enterprise cooperation does not adapt to the changes of external environment.

Second, the motivation for enterprises to participate in the industry-education integration is insufficient. And the cooperation between schools and enterprises is not deep enough. Talent training, discipline construction and faculty construction are not closely combined with the actual production of the enterprise, which leads to difficulties in industry docking education and insufficient in-depth cooperation between schools and enterprises.

Third, innovation and entrepreneurship have little effect on the integration of industry and education. The traditional production-learning-research training mode lacks the guidance of innovative and entrepreneurial thinking in the whole process of education. So it fails to explore the depth of the industry-education integration. Students show a lack of innovation and entrepreneurship ability.

\section{ESTABLISHMENT OF PRODUCTIONTRANING BASE OF INDUSTRY-EDUCTION INTEGRATION}

The training and practice of technology and skill talents is carried out by the school's intelligent manufacturing production training base. Combined with the education supply and industrial demand of the intelligent manufacturing talents in China, it takes the production training base in the intelligent manufacturing industrial park built by the school as the carrier of deepening the industryeducation integration. It explores the talent training mode of the construction of intelligent manufacturing professional group. And it constructs a suitable training mode. In order to meet the requirements of intelligent manufacturing industry for talent structure training, the training and practice methods of technology and skill talents under the mode of industry education integration of higher vocational colleges corresponding to the professional development of our university are proposed [2].

Intelligent manufacturing is a high-performance industry. The related industries will become the leading industry in the future industrial development field in the world. Chinese intelligent manufacturing industry maintains a relatively rapid growth rate.

The university is building the university city science and technology ecosystem. The university city science and technology park is a platform and service institution based on relevant colleges and universities, combining the advantages of comprehensive intellectual resources of colleges and universities with other social advantages resources, providing support for the transformation of scientific and technological achievements of colleges and universities, incubation of high-tech enterprises, training of innovative and entrepreneurial talents, and integration of production, learning and research.

As the carrier of deepening the policy of industry-education integration, the productive training base of intelligent manufacturing industrial park forms a consortium with the government, enterprises and schools, deepens the reform of vocational education and higher education in our school, plays an important role of the enterprise, promotes the allround integration of the supply side and industrial demand side structural elements of talent training, and cultivates a large number of high-quality innovative talents and technical talents to provide strong support for accelerating the construction of industrial system of coordinated development of real economy, scientific and technological innovation, modern finance and human resources.

The intelligent manufacturing industrial park is an intelligent assembly line of electronics and intelligent production line of new energy vehicle components jointly built by the school and company, which provides a highlevel, professional and advanced manufacturing training base for deepening the industry-education integration. The intelligent manufacturing industrial park will implement the mode of school-enterprise cooperation, school-enterprise co-construction, school-enterprise co-operation, and create a precedent for the integration of industry and education in the field of intelligent manufacturing.

\section{ANALYSIS OFTHEMODE OFTALENTTRANINGINTHE INTEGRATION OF INDUSTRY AND EDUCATION}

Relying on the productive training base built by the school, this research focuses on deepening the industry-education integration. Carrying out school enterprise cooperation is to jointly cultivate intelligent manufacturing professionals. Building a curriculum system is to meet the needs with the cultivation of students' technical skills. A batch of highquality technical and technical talents are trained through order-training and apprenticeship. It provides a training base for teachers and improve the teaching quality of doublequalification teachers. It cultivates innovative talents through establishing professional construction committee by schools and enterprises to ensure the deep industryeducation integration.

First, we will jointly build a training base, train intelligent manufacturing professionals, and promote the discipline construction of industrial robot technology, intelligent control technology and other disciplines to adapt to the industrial upgrading and transformation. In the process of building production line training base in the intelligent manufacturing industrial park, the mode of collegeenterprise is adopted. The participation of enterprises is not limited to the construction of student practice base, but to enable higher vocational students to carry out the integrated training of quality and skills. It need implement the modern vocational education system with cooperative education, cooperative employment, cooperative construction and cooperative development. The construction of the project will promote the discipline construction of intelligent manufacturing professional [3].

Second, based on the intelligent manufacturing production training base, with the cultivation of students' skills as the core, it will build a modular professional curriculum system [4]. Under the new requirements of industrial transformation and upgrading, according to the requirements of professional posts, it need students to 


\section{ACKNOWLEDGMENT} and then carry out the learning of professional main courses. Third, based on the intelligent manufacturing production training base, it will innovative personnel training mode including order-training and apprenticeship [5]. Order training need build employment platform, use the resources of both schools and enterprises, carry out practical ability training according to the requirements of intelligent manufacturing post group, and form a talent training program mode characterized. The modern apprenticeship training mode means that we will cultivate high-quality technical and technical talents serving the front line with the craftsman-spirit. The practice course is carried out under the guidance of the technical personnel of the enterprise until the students complete the operation independently.

Fourth, based on the intelligent manufacturing production training base, the industry-education integration will run through the whole process of teacher training. It will cultivate the double teacher teaching team, and realize the improvement of ability. Using the school production line training base, it will strengthen the on-the-job training of teachers' enterprises to ensure the quantity and quality [6]. Fifth, based on the intelligent manufacturing production training base, it will build an innovation and entrepreneurship platform. With the production and other manufacturing capabilities as the link, it will promote an open platform for all-round innovation in the whole process of production and manufacturing, the whole industrial chain, and the whole product life cycle. It will strive to cultivate innovative talents, and practically promote production, learning, research and application. The intelligent manufacturing industrial park will build a three-dimensional integrated platform of innovation and entrepreneurship platform, business incubation platform and intelligent manufacturing training production training base [7].

Sixthly, based on the intelligent manufacturing production training base, the school and the enterprise jointly set up a professional construction committee to lead the whole process of higher vocational personnel training and ensure the depth of the industry-education integration [8]. Around the industrial demand of professional construction docking, it will establish a dynamic adjustment mechanism of professional. It will improve the talent training program, participate in the systematic work process, project-based curriculum construction and practical training project development, and drive the development of intelligent manufacturing professional group.

\section{CONCLUSION}

It takes the intelligent manufacturing industrial park as the support. Based on this park, it establishes the productive training base. It realizes the school enterprise cooperation and the talent cultivation seamless docking. Thus, it realizes the real thorough industry-education integration and carries on the talent cultivation pattern research and the practice, so as to provide the high quality technical skilled talents for the advanced manufacturing industry and serve the regional economic development.
This research is supported by the higher education teaching reform research project of Chongqing Education Commission (NO. 193468).

\section{REFERENCES}

[1] Xie Xiaozhen, Research on the Mechanism Design of "Industry-education Integration". Research on Higher Engineering Education,2019(5):81-87.

[2] Tang Ling, Study on the Training of Multi-skilled Workers in Order to Meet "Chinese Manufacturing 2025". Research on Technology Economy and Management,2016(6):30-35.

[3] Xu Fang, the Integration of Industry and Education and the Construction of Professional Training Course System:Taking the Practice of Hunan Petrochemical Institute in Enterprise $\mathrm{C}$ as an Example. Science and Technology in Chinese Universities,2019(9):62-64.

[4] Pei Zhaoying, Practice and Exploration of the Integration of Industry and Education to Train Automobile Talents. Internal Combustion Engine \& Parts, 2019(3):252-253.

[5] Sun Xiaoli, Zheng Yi, etc, Implementation and Discussion of Modern Apprenticeship Teaching Mode. Geospatial Information,2019(2):110-113.

[6] Chen Baohua, Research on the Development of Teachers' Teaching Ability in Private Colleges and Universities from the Perspective of Industry Education Integration, Education Research Monthly,2019(8):97102.

[7] Yang Yang, A Probe into the Path to Deepen Industry-Education Integration of Higher Vocational Colleges Under the Background of Innovation and Entrepreneurship. Journal of Nanning Polytechnic,2019 (1) $47: 50$.

[8] Zhang Huili, Research on the cultivation path of industry education integrated enterprise. Baijia Lunyuan,2019(9):152-155. 